\title{
Comparing a Social and Communication App, Telephone Intervention, and Usual Care for Diabetes Self-Management: 3-Arm Quasiexperimental Evaluation Study
}

Ching-Ju Chiu ${ }^{1}$, PhD; Yung-Chen $\mathrm{Yu}^{2}$, MS; Ye-Fong Du ${ }^{3}$, MD, MS; Yi-Ching Yang ${ }^{4}$, MD, MS; Jou-Yin Chen ${ }^{5}$, MS; Li-Ping Wong ${ }^{6}, \mathrm{PhD}$; Chanuantong Tanasugarn ${ }^{7}, \mathrm{PhD}$

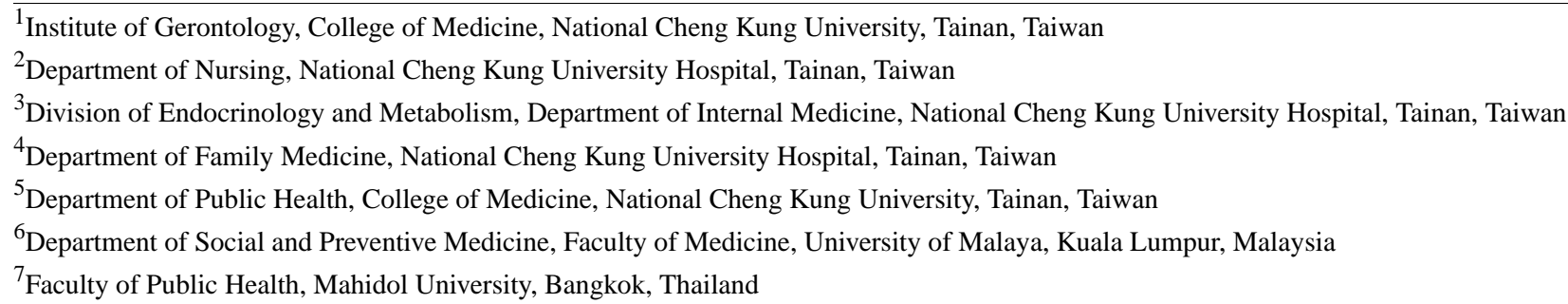

Corresponding Author:

Ye-Fong Du, MD, MS

Division of Endocrinology and Metabolism

Department of Internal Medicine

National Cheng Kung University Hospital

No. 138, Shengli Road, North District

Tainan, 70403

Taiwan

Phone: 88662353535 ext 4577

Email: n043328@mail.hosp.ncku.edu.tw

\section{Abstract}

Background: Many technology-assisted innovations have been used to manage disease. However, most of these innovations are not broadly used by older adults due to their cost. Additionally, disease management through technology-assisted innovations has not been compared with other interventions.

Objective: In this study, we tested the employment of a free and widely used social and communication app to help older adults with diabetes manage their distress and glycemic control. We also compared the effectiveness of the app with 2 other methods, namely telephone and conventional health education, and determined which subgroup experiences the most effects within each intervention.

Methods: Adults aged $\geq 50$ years with type 2 diabetes were recruited from Southern Taiwan (N=231) and were allocated to different 3-month interventions. Informed consent was obtained at the Ministry of Science and Technology and approved by the National Cheng Kung University Hospital Institutional Review Board (No. A-ER-102-425).

Results: Participants in the mobile-based group had significant reductions in hemoglobin A1c compared with the telephone-based and usual care groups (mean changes of $-0.4 \%, 0.1 \%$, and $0.03 \%$, respectively; $P=.02$ ). Diabetes-specific distress decreased to a greater extent in the mobile-based group compared to the other 2 groups (mean changes of $-5.16,-3.49$, and -2.44 , respectively, $P=.02$ ). Subgroup analyses further revealed that the effects on reducing blood glucose levels in the social and communication app groups were especially evident in patients with lower distress scores, and diabetes-related distress was especially evident in participants who were younger than 60 years or had higher educational levels.

Conclusions: The findings of this study inform more flexible use of social and communication apps with in-person diabetes education and counselling.

(JMIR Mhealth Uhealth 2020;8(6):e14024) doi: $\underline{10.2196 / 14024}$

\section{KEYWORDS}

diabetes; self-management; depression symptoms; distress; middle-aged and older adults 


\section{Introduction}

Existing interventions for people with diabetes generally involve group or individual counseling for self-management education and support [1-3]. The use of technology to collect data through the internet to manage disease is increasing; many such studies focus on diabetes, including monitoring glucose or vital signs through mobile apps or websites, messaging reminders through email or SMS text messaging for self-care skills, and improving emotional status [4-8]. In recent years, mobile phones have become an increasingly important platform for the delivery of health interventions; they can be used to help individuals manage their health and disease condition [9-13]. Web-based structured integrated care has been employed by several research teams to provide information for diabetes education, record blood glucose readings, and provide personal feedback [14-16]. Many mobile apps have been developed for diabetes care. Better outcomes were observed for mobile apps that provided 2-way communication between people with diabetes and their health care team $[17,18]$. However, most of these interventions require the development of a structured website or a diabetes-specific mobile app; these are not translated into many languages, which limits their universal use [19].

Currently, $53 \%$ of adults age 65 and older use the Internet in Taiwan [20], and one third of older persons who are online use social networking sites such as Facebook, LinkedIn, and LINE, which were listed as age-friendly apps in 2012 [21]. Some traditional technologies (eg, telephones, video game consoles) have been utilized to conduct health-related interventions. New technologies such as exoskeleton human body posturizers [22], the Nintendo Wii console [23], and virtual reality gaming [24] have also been investigated to assist older people in improving their balance and have been shown to decrease both the fear of falling and the number of falls. For diabetes control apps in Taiwan, the National Health Insurance program developed an internet platform called My Health Bank. My Health Bank provides patients' medical records over the past 3 years; patients can use it to record their own health data, such as BMI and blood test results, including fasting plasma glucose, hemoglobin $\mathrm{A}_{\mathrm{c}}\left(\mathrm{HbA}_{1 \mathrm{c}}\right)$, and lipid profiles. Physicians can quickly understand their patients' physical condition, treatment status, and medical examinations through this app [25]. Moreover, many studies have explored the use of new technologies such as websites or mobile apps to help with disease or health management, such as smoking cessation [26,27], medication management [28], and prevention of excessive gestational weight gain and associated maternal and child health consequences [29]. However, few existing studies have focused on the effects of existing, freely available communication apps (eg, Facebook Messenger, LINE, WhatsApp Messenger) among middle-aged and older adults; therefore, the effectiveness of social networking interventions to address the health issues of middle-aged and older adults is not certain. One of the most age-friendly and easy-to-use social network applications is known as LINE; it does not restrict the learning pace, time, or space of learners, and users also benefit from the interaction in this mobile app [30]. In addition, information about diabetes self-management can be easily transmitted through text messages, photographs, and short videos to enable people to use this information in daily life. LINE is one of the most popular apps for social communication in Taiwan [31]. However, whether this tool can be employed in self-management education and support to help older adults manage their diabetes is unknown.

According to the American Association of Diabetes Educators (AADE), 7 behavioral indicators [4] are critical to enhancing the self-care abilities of people with diabetes and to helping them reach their optimal goal of glycemic control through education and various support resources. These indicators, called the AADE7 Self-Care Behaviors, are (1) healthy eating, (2) being active, (3) monitoring, (4) taking medication, (5) problem solving, (6) reducing risks, and (7) healthy coping. The results of one study indicated that most diabetes apps do not adhere to more than 2 AADE7 self-care behavior guidelines [32]. Therefore, the aims of this study were to test 3 intervention modes that were developed based on the AADE7 self-care behavior guidelines, including mobile-based, telephone-based, and usual care interventions. We compared the impact of the mobile-based, telephone-based, and usual care interventions on diabetes-related distress, depressive symptoms, and glycemic control in middle-aged and older adults living in the community. We also compared the degrees of acceptance within the 3 groups to determine which subgroup experienced the most effects.

\section{Methods}

This study was a 3 -arm quasiexperimental design. We recruited participants aged $\geq 50$ years with type 2 diabetes through a medical chart review. Exclusion criteria were people with renal dysfunction (creatinine $\geq 1.5$ milligrams per deciliter) or who were receiving dialysis treatment. People who were diagnosed with dementia, cognitive impairment, or major depression were also excluded. We recruited our participants from the endocrine and family medicine clinics of a medical center in Southern Taiwan. Informed consent was obtained at the Ministry of Science and Technology, and the study was approved by the National Cheng Kung University Hospital Institutional Review Board (No. A-ER-102-425).

In the mobile-based group, participants were required to own a mobile device and to be capable of using the mobile device $(n=49)$. Participants who did not have a mobile device and access to the internet at home were randomized to either the telephone-based interview group $(n=91)$ or the usual care group $(\mathrm{n}=91)$.

Each group was provided with diabetes-related self-care information and provided with emotional support through usual care. In the mobile-based intervention group, in addition to the participants' usual care, we used a communication app called LINE to send multimedia messages about diabetes self-management for 12 weeks. LINE is a free instant communication service. In Taiwan, over $90 \%$ of people install LINE on their mobile devices [33]. LINE users can set up their own accounts using their telephone number or email address and can link with friends by telephone number or LINE ID. When the participants were ready to join our study, we checked their telephone number or LINE ID and linked it to our research 
account, and a welcome message was sent to the individual accounts of the participants. The research team verified whether the messages we sent to each individual account were marked as "read." The participants were also able to interact with our research team by LINE. Messages were sent 3 times a week, and the participants received an average of 5 messages per week. Structural diabetes health education modules were developed according to AADE7 guidelines. We included 6 of the behavioral indicators in our messages: healthy eating (eg, how to select appropriate food and observe amounts of sweeteners); being active (eg, suitable ways to exercise and precautions related to exercise); monitoring (eg, the standard glucose values before and after a meal); taking medication (eg, what to do if they forgot to take their medicine); (5) problem solving (eg, how to relax and search for health information); and (6) reducing risk (eg, foot care skills). The topics of the weekly messages are shown in Textbox 1 and sample messages are shown in Multimedia Appendix 1

In the telephone-based intervention group, the participants received 3-4 phone calls lasting 30-60 minutes each from a diabetes health educator. The first call explored the participant's diet, sleep habits, exercise level, and blood glucose control as well as their general and diabetes-specific health conditions. The people with diabetes were asked to talk about their feelings and lifestyle changes after they were diagnosed with diabetes. The goal was to understand their daily routines, thoughts, worries, related feelings, and behavior. According to the baseline assessment, in the second and subsequent phone calls, the assistants asked the participants to discuss self-care problems related to diabetes and their feelings about the disease in addition to the AADE7 modules. The usual care group received a routine intervention for people with diabetes in hospital, where the participants received 5-10 minutes of usual care (including a nutrition consultation, exercise guidance, medication, and other self-care skills related to diabetes) once every 3 months by family medicine physicians in family medicine outpatient departments and by certified diabetes educators at diabetic health education clinics.

We collected data on the health conditions of the patients, such as the year they were diagnosed with diabetes, body weight, height, anti-diabetic therapy, and recent $\mathrm{HbA}_{1 \mathrm{c}}$ levels through a medical chart review. We reviewed the medical record data related to complications such as diabetic foot, hypertension, and stroke. We also collected self-reported data about sociodemographic characteristics, health behavior, and psychological well-being. Sociodemographic factors included age, sex, education, ethnicity, and marital status. The educational levels were divided into 6th grade and below, grades 7-12, and grades 13 and above. The options in the ethnicity category were Taiwanese, mainlander, Hakka, and aborigine. The possible answers to the question on marital status were widowed, married and living with spouse, and other (divorced, separated, or unmarried). The health behavior variables included the frequency and time of exercise, dietary habits, tobacco use, alcohol use, and the amount of alcohol consumed. These data were collected at baseline and after the intervention.

Diabetes-specific emotional distress was measured using the Problem Areas in Diabetes (PAID) scale. It contains 20 questions; each question describes a problem that a person with diabetes may have. The PAID scale uses a 5-point item scale: $1=$ Not a problem, $2=$ Minor problem, $3=$ Moderate problem, $4=$ Somewhat serious problem, and $5=$ Serious problem. A higher PAID score indicates greater emotional distress related to diabetes. The total scale of PAID is $0-100$, and the commonly used cutoff score of $\geq 40$ was used to indicate elevated levels of diabetes-specific emotional distress [34].

Depressive symptoms were measured with the Center for Epidemiological Studies Depression Scale (CES-D), which is a self-reported questionnaire. The CES-D contains 20 questions. It has been found to have good validity and reliability for different races and ages [35]. In the pretest, we used the brief CES-D. The brief CES-D contains 10 questions on a 4-point scale to classify the depression status of older persons in the most recent week, with possible answers of "not at all," "usually," and "always." The short-form CES-D scale ranges from 0-30, with a higher CES-D score indicating a higher level of depression. The cutoff scores for depressive symptoms were $\geq 16$ for the full-length questionnaire and $\geq 10$ for the 10 -item version for older adults [36,37]. 
Textbox 1. The topics of the weekly SMS text messages.

\section{Week 1. Healthy eating}

- Regular diet and principles of eating out for people with diabetes

- Appropriate food and desserts for people with diabetes

- Awareness of artificial sweeteners

- Low calorie diet education

\section{Week 2. Healthy eating}

- Recording daily amounts of milk, starch, vegetables, fruits, beans, and meat

- Carbohydrate counting

- Glycemic indices of common fruits and low fat food groups

\section{Week 3. Being active}

- The importance and principles of exercise for people with diabetes

- Photographs of a variety of exercise positions for middle-aged and older adults, such as warmups and calisthenics

\section{Week 4. Being active}

- Photographs of a variety of exercise positions, such as those promoting strength, endurance, and flexibility

\section{Week 5. Taking medication}

- Insulin group:

- Myths and facts about insulin injections

- Introduction to different types of insulin and their durations of use

- Oral drugs group:

- Directions and reminders for taking medication

- Tips on what to do if they forget to take their medication

\section{Week 6. Taking medication}

- Insulin group:

- Tips on injection skills and equipment

- $\quad$ Travel guidelines for people with diabetes

- Oral drugs group:

- Myths and facts about taking oral drugs

- Travel guidelines for people with diabetes

\section{Week 7. Monitoring}

- The importance of glycemic monitoring

- Appropriate times and frequency of monitoring

- $\quad$ The meaning of fasting glucose

\section{Week 8. Monitoring}

- Hypoglycemia and hyperglycemia symptoms

- Common causes of hypoglycemia and hyperglycemia

- Tips for preventing hypoglycemia and hyperglycemia

\section{Week 9. Reducing risk}

- Causes of diabetic foot 
- Symptoms of diabetic foot

- $\quad$ Self-care skills for diabetic foot

- Tips for selecting appropriate shoes for people with diabetes

Week 10. Reducing risk

- $\quad$ Self-care skills when sick

- Diabetic retinopathy and eye exam reminder

Week 11. Problem solving

- $\quad$ Stress and diabetes

- Tips for biopsychosocial adjustment, including developing good hobbies and positive thinking

Week 12. Problem solving

- How to search for correct information about diabetes

\section{Results}

The baseline characteristics of the 3 groups in our study are shown in Table 1. No significant differences were observed in terms of gender, marital status, antidiabetic therapy, eye problems, foot problems, hypertension, lung disease, heart disease, cancer, arthritis, smoking, or exercise behavior across the 3 groups; also, no significant differences were observed in the means of the duration of diabetes, $\mathrm{HbA}_{1 \mathrm{c}}$ level, BMI, or CES-D score. However, participants in the mobile-based intervention group $(n=49)$ were significantly younger and had higher educational levels than those in the telephone-based group ( $n=91)$ and usual care group $(n=91)$. Also, participants in the mobile-based intervention group had higher PAID scores than those in the other 2 groups at baseline. These factors were used as stratification variables in our subgroup analysis.

Table 2 presents the pretest and posttest $\mathrm{HbA}_{1 \mathrm{c}}, \mathrm{CES}-\mathrm{D}$, and PAID scores and the differences between them across the 3 groups. Participants in the mobile-based group showed significant improvement in their $\mathrm{HbA}_{1 \mathrm{c}}$ levels after the intervention (posttest to pretest: $-0.40 \%, P=.04$ ) and PAID scores (posttest to pretest: $-5.16, P=.01$ ). We further used the Kruskal-Wallis test to examine the differences in the main outcomes across the groups. Our results showed that changes in the participants' $\mathrm{HbA}_{1 \mathrm{c}}$ levels in the mobile-based intervention group (posttest to pretest: -0.40\%) were significantly higher than those in the telephone-based group (posttest to pretest: $0.10 \%$ ) and the usual care group (posttest to pretest: $0.03 \%$ ). Also, the absolute improvement of the PAID score in the mobile-based intervention group (posttest to pretest:
-5.16) was significantly higher than that of the telephone-based group (posttest to pretest: -3.49 ) and the usual care group (posttest to pretest: -2.44$)$.

Due to the significant differences shown in Table 1 and the possible confounding associated with age, educational level, and depression symptoms at baseline, we further conducted a sensitivity analysis that stratified the participants by age, educational level, and baseline PAID score (Table 3). It was found that for participants aged $<60$ years, diabetes distress was significantly reduced in both the mobile-based intervention group (score -7.45, $P=.01$ ) and the telephone-based intervention group (score $-4.87, P=.008$ ). For participants with educational levels $\geq 7$ grades, diabetes distress was also significantly reduced in both the mobile-based intervention group (score -8.80 , $P=.001$ ) and the telephone-based intervention group (score $-7.44, P=.008)$. In addition, participants in the mobile-based intervention group experienced a greater reduction in diabetes distress than those in the telephone-based intervention group, regardless of subgroup: age <60 years (the differences in the PAID score were mobile -7.45 ; telephone -4.87 ; usual care -4.14 ) or education $\geq 7$ th grade (the differences in the PAID score were mobile -8.80 ; telephone -7.44 ; usual care -5.00). Furthermore, we found that if the participants' PAID was above the average (3.75), diabetes distress was significantly reduced in the mobile-based (score $-6.89, P=.005$ ), telephone-based (score $-9.01, P<.001$ ), and usual care groups (score -7.90 , $P=.001)$ after the intervention. In addition, for participants with diabetes distress scores lower than the median, only the mobile-based intervention group exhibited significantly reduced $\mathrm{HbA}_{1 \mathrm{c}}$ levels (score $-0.31 \%, P=.04$ ). 
Table 1. The baseline sociodemographic, clinical, and psycho-behavioral characteristics of the mobile-based, telephone-based, and usual care groups $(\mathrm{N}=231)$.

\begin{tabular}{|c|c|c|c|c|}
\hline Characteristic & $\begin{array}{l}\text { Mobile-based group } \\
(\mathrm{n}=49)\end{array}$ & $\begin{array}{l}\text { Telephone-based group } \\
(\mathrm{n}=91)\end{array}$ & $\begin{array}{l}\text { Usual care group } \\
(\mathrm{n}=91)\end{array}$ & $P$ value \\
\hline \multicolumn{5}{|l|}{ Sociodemographic variables } \\
\hline Age (years), mean (SD) & $58.66 .0)$ & $64.70(8.30)$ & $64.70(9.50)$ & $<.001$ \\
\hline Male gender, $\mathrm{n}(\%)$ & $32(65)$ & $50(55)$ & $44(48)$ & .16 \\
\hline \multicolumn{5}{|l|}{ Education level, n (\%) } \\
\hline Grade 6 and below & $1(2)$ & $37(41)$ & $35(39)$ & $<.001$ \\
\hline Grades 7-12 & $22(45)$ & $32(35)$ & $35(39)$ & \\
\hline Grade 13 and above & $26(53)$ & $22(24)$ & $21(23)$ & \\
\hline Married or partnered, n (\%) & $43(88)$ & $71(78)$ & $75(82)$ & .16 \\
\hline \multicolumn{5}{|l|}{ Diabetes and other clinical variables } \\
\hline Duration of diabetes (years), mean (SD) & $7.5(6.1)$ & $10.60(8.60)$ & $10.40(8.18)$ & .10 \\
\hline \multicolumn{5}{|l|}{ Diabetes treatment, $\mathrm{n}(\%)$} \\
\hline Diet and exercise & $7(14)$ & $5(6)$ & $10(11)$ & .11 \\
\hline Oral medication & $31(63)$ & $58(63)$ & $71(78)$ & \\
\hline Insulin & $11(23)$ & $20(23)$ & $10(11)$ & \\
\hline $\mathrm{HbA}_{1 \mathrm{c}}{ }^{\mathrm{a}}$ level (\%), mean (SD) & $7.6(1.5)$ & $7.6(1.6)$ & $7.6(1.3)$ & .94 \\
\hline BMI (kilograms per square meter), mean (SD) & $25.9(3.7)$ & $25.80(3.30)$ & $25.90(4.40)$ & .10 \\
\hline Eye problems, n (\%) & $4(8)$ & $7(8)$ & $10(11)$ & .71 \\
\hline Foot problems, n (\%) & $2(4)$ & $10(11)$ & $5(6)$ & .22 \\
\hline Hypertension, $\mathrm{n}(\%)$ & $19(39)$ & $49(54)$ & $45(50)$ & .23 \\
\hline Lung disease, $\mathrm{n}(\%)$ & $0(0)$ & $2(2)$ & $2(2)$ & .15 \\
\hline Heart disease, $\mathrm{n}(\%)$ & $9(18)$ & $11(12)$ & $7(8)$ & .17 \\
\hline Cancer, n (\%) & $2(4)$ & $6(7)$ & $8(9)$ & .57 \\
\hline Arthritis, n (\%) & $2(4)$ & $10(11)$ & $8(9)$ & .38 \\
\hline \multicolumn{5}{|l|}{ Psychobehavioral variables } \\
\hline Smoking, n (\%) & $4(8)$ & $13(14)$ & $4(4)$ & .07 \\
\hline \multicolumn{5}{|l|}{ Exercise, n (\%) } \\
\hline Never & $4(9)$ & $18(20)$ & $15(17)$ & .09 \\
\hline 1-2 times or less than 90 minutes per week & $16(32)$ & $17(19)$ & $13(14)$ & \\
\hline $\begin{array}{l}\text { More than } 3 \text { times and }>90 \text { minutes per } \\
\text { week }\end{array}$ & $29(60)$ & $56(61)$ & $63(69)$ & \\
\hline CES-D ${ }^{b}$ score $(0-30)$, mean (SD) & $6.8(5.1)$ & $5.20(3.90)$ & $5.60(4.80)$ & .14 \\
\hline $\begin{array}{l}\text { Diabetes-specific emotional distress score } \\
\left(\text { PAID }^{\mathrm{c}}, 0-100\right) \text {, mean (SD) }\end{array}$ & $13.5(12.4)$ & $5.40(7.40)$ & $5.20(9.30)$ & $<.001$ \\
\hline
\end{tabular}

${ }^{\mathrm{a}} \mathrm{HbA}_{1 \mathrm{c}}$ : hemoglobin $\mathrm{A}_{\mathrm{c}}$

${ }^{\mathrm{b}}$ CES-D: Center for Epidemiological Studies Depression Scale

${ }^{c}$ PAID: Problem Areas in Diabetes Scale 
Table 2. Pretest and posttest $\mathrm{HbA}_{1 \mathrm{c}}, \mathrm{CES}-\mathrm{D}$, and PAID scores across the 3 groups and the differences between them.

\begin{tabular}{|c|c|c|c|c|c|c|c|c|}
\hline \multirow[t]{2}{*}{ Variable } & \multicolumn{2}{|c|}{ Mobile-based group } & \multicolumn{2}{|c|}{ Telephone-based group } & \multicolumn{2}{|c|}{ Usual care group } & \multicolumn{2}{|c|}{ Kruskal-Wallis test } \\
\hline & Mean (SD) & $P$ value $^{\mathrm{a}}$ & Mean (SD) & $P$ value $^{\mathrm{a}}$ & Mean (SD) & $P$ value $^{\mathrm{a}}$ & Chi-square (2) & $P$ value \\
\hline \multicolumn{9}{|l|}{$\operatorname{HbA}_{1 c}{ }^{b}(\%)$} \\
\hline Pretest & $7.8(1.49)$ & .04 & $7.64(1.56)$ & .38 & $7.67(1.28)$ & .78 & 8.3 & .02 \\
\hline Posttest & $7.18(1.05)$ & & $7.74(1.47)$ & & $7.70(1.18)$ & & & \\
\hline Difference $^{c}$ & $-0.40(1.24)$ & & $0.10(1.12)$ & & $0.03(1.1)$ & & & \\
\hline \multicolumn{9}{|l|}{ CES-D ${ }^{d}$ score } \\
\hline Pretest & $6.78(5.08)$ & .31 & $5.19(3.91)$ & $<.01$ & $5.59(4.75)$ & .03 & 4.0 & .13 \\
\hline Posttest & $7.95(5.76)$ & & $3.84(2.40)$ & & 4.47 (3.09) & & & \\
\hline Difference $^{c}$ & $0.98(6.14)$ & & $-1.34(4.16)$ & & $-1.12(4.86)$ & & & \\
\hline \multicolumn{9}{|l|}{ PAID $^{\mathrm{e}}$ score } \\
\hline Pretest & $13.52(12.40)$ & .01 & $5.44(7.39)$ & $<.01$ & $5.24(5.29)$ & .03 & 7.6 & .02 \\
\hline Posttest & $9.31(9.79)$ & & $2.06(6.14)$ & & $2.90(4.79)$ & & & \\
\hline Difference $^{c}$ & $-5.16(12.58)$ & & $-3.49(9.97)$ & & $-2.44(10.60)$ & & & \\
\hline
\end{tabular}

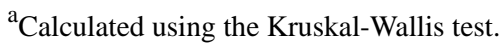

${ }^{\mathrm{b}} \mathrm{HbA}_{1 \mathrm{c}}$ : hemoglobin $\mathrm{A} 1_{\mathrm{c}}$.

${ }^{\mathrm{c}}$ Difference: posttest value - pretest value.

${ }^{\mathrm{d}}$ CES-D: Center for Epidemiological Studies Depression Scale.

ePAID: Problem Areas in Diabetes Scale. 
Table 3. Sensitivity analysis comparing the intervention effects in the different subgroups.

\begin{tabular}{|c|c|c|c|c|c|c|c|c|c|c|c|}
\hline \multirow{2}{*}{$\begin{array}{l}\text { Subgroup and } \\
\text { effect }\end{array}$} & \multicolumn{3}{|c|}{ Mobile-based group } & \multicolumn{3}{|c|}{ Telephone-based group } & \multicolumn{3}{|c|}{ Usual care group } & \multicolumn{2}{|c|}{ Kruskal-Wallis test } \\
\hline & $\mathrm{n}$ & Score & $P$ value & $\mathrm{n}$ & Score & $P$ value & $\mathrm{n}$ & Score & $P$ value & Chi-square (2) & $P$ value \\
\hline \multicolumn{12}{|c|}{ Age $\geq 60$ years $(n=138)$} \\
\hline$\Delta \mathrm{HbA}_{1 \mathrm{c}}{ }^{\mathrm{a}}(\%)$ & 19 & -0.42 & .09 & 61 & 0.25 & .03 & 58 & 0.08 & .62 & 6.52 & .04 \\
\hline$\Delta$ CES-D ${ }^{\mathrm{b}}$ & & 2.35 & .21 & & -1.44 & .01 & & -1.11 & .09 & 6.43 & .04 \\
\hline$\Delta \mathrm{PAID}^{\mathrm{c}}$ & & -2.06 & .49 & & -2.82 & .04 & & -1.49 & .15 & 3.93 & .14 \\
\hline \multicolumn{12}{|c|}{ Age $<60$ years $(n=93)$} \\
\hline$\Delta \mathrm{HbA}_{1 \mathrm{c}}(\%)$ & 30 & -0.38 & .19 & 30 & -0.19 & .51 & 33 & -0.05 & .76 & 1.27 & .53 \\
\hline$\Delta$ CES-D & & -0.04 & .97 & & -1.14 & .12 & & -1.16 & .19 & 0.36 & .84 \\
\hline$\triangle \mathrm{PAID}$ & & -7.45 & .01 & & -4.87 & .008 & & -4.14 & .11 & 4.62 & .10 \\
\hline \multicolumn{12}{|c|}{ Education $\geq 7$ grades $(n=69)$} \\
\hline$\Delta \mathrm{HbA}_{1 \mathrm{c}}(\%)$ & 26 & -0.25 & .31 & 22 & 0.12 & .46 & 21 & 0.08 & .55 & 1.71 & .42 \\
\hline$\Delta$ CES-D & & 0.09 & .94 & & -0.71 & .26 & & 0.00 & 1.000 & 0.14 & .93 \\
\hline$\Delta$ PAID & & -8.80 & .001 & & -7.44 & .008 & & -5.00 & .06 & 3.24 & .20 \\
\hline \multicolumn{12}{|c|}{ Education $<7$ grades $(n=162)$} \\
\hline$\Delta \mathrm{HbA}_{1 \mathrm{c}}(\%)$ & 23 & -0.57 & .07 & 69 & 0.10 & .50 & 70 & 0.02 & .91 & 8.32 & .02 \\
\hline$\Delta$ CES-D & & 2.18 & .20 & & -1.54 & .007 & & -1.45 & .02 & 4.24 & .12 \\
\hline$\Delta$ PAID & & -0.22 & .95 & & -2.26 & .05 & & -1.70 & .18 & 4.61 & .10 \\
\hline \multicolumn{12}{|c|}{ PAID mean score $\geq 3.75(n=34)$} \\
\hline$\Delta \mathrm{HbA}_{1 \mathrm{c}}(\%)$ & 17 & -0.41 & .08 & 6 & 0.15 & .33 & 11 & -0.05 & .78 & 3.75 & .15 \\
\hline$\Delta$ CES-D & & 1.27 & .28 & & -1.23 & .09 & & -2.16 & .01 & 4.36 & .11 \\
\hline$\Delta$ PAID & & -6.89 & .005 & & -9.01 & $<.0001$ & & -7.90 & $<.001$ & 1.68 & .43 \\
\hline \multicolumn{12}{|c|}{ PAID mean score <3.75 $(n=197)$} \\
\hline$\Delta \mathrm{HbA}_{1 \mathrm{c}}(\%)$ & 32 & -0.31 & .04 & 85 & 0.06 & .73 & 80 & 0.09 & .59 & 4.78 & .09 \\
\hline$\Delta$ CES-D & & -0.43 & .74 & & -1.44 & .01 & & -0.35 & .58 & 2.13 & .35 \\
\hline$\Delta$ PAID & & 3.04 & .10 & & 1.78 & .16 & & 1.62 & .009 & 4.80 & .09 \\
\hline
\end{tabular}

${ }^{\mathrm{a}} \mathrm{HbA}_{1 \mathrm{c}}$ : hemoglobin $\mathrm{A}_{1 \mathrm{c}}$.

${ }^{\mathrm{b}}$ CES-D: Center for Epidemiological Studies Depression Scale.

${ }^{\mathrm{c}}$ PAID: Problem Areas in Diabetes Scale.

\section{Discussion}

\section{Principal Findings}

This study examined the effectiveness of a mobile-based intervention on the glycemic control of people with diabetes, depressive symptoms, and diabetes-specific distress in comparison with telephone-based intervention and usual care. The results provide evidence that the mobile-based intervention has the greatest potential to improve glycemic control and reduce diabetes-specific distress among the 3 interventional methods. For participants in the mobile-based group who were less than 60 years of age or who had higher educational levels at baseline, their distress scores decreased more dramatically than those of the participants in the other 2 groups after the intervention. In addition, for participants with distress scores below the average at baseline, those who received the intervention based on the social and communication app LINE had significantly improved $\mathrm{HbA}_{1 \mathrm{c}}$ values, which was not observed in the telephone-based group or usual care group.

Previous studies evaluating technology-enabled self-management education mostly used web-based structured diabetes education, time-consuming nurse coaching, and online educational discussion groups to aid diabetes self-management [8]. Although these approaches can reduce depressive symptoms and diabetes-related distress, they are labor-intensive and may be expensive. In the present study, we utilized a patient-centered approach and a freely available social app. We sent text and photographic messages based on the AADE's 7 indicators for diabetes self-management to middle-aged and older adults through the free social and communication app LINE, which 
the participants were familiar with. In addition, we provided social support, problem solving, and communication with professionals through the LINE app. With figure-rich messages for diabetic education, the LINE app is suggested to be an effective platform to execute diabetes education and support; it may improve diabetes glycemic control and reduce diabetes-related distress more than usual care, supporting previous studies indicating the strength of mobile phones in this area [38]. The strengths of social and communication apps include their ability to send multimedia messages and free video calls; also, using mobile-based devices, participants can browse their messages repeatedly and magnify the image-based messages, which addresses the decline in cognitive functioning required for older adults to manage their disease. Also, the bright colors and clear font size in the photo messages are age-friendly and help older adults avoid eye fatigue [39]. We found that the participants not only experienced decreased diabetes distress but also had increased glycemic control performance.

The success of the application of the LINE app in diabetes care in middle-aged and older adults in Taiwan may be due to their cultural background of the participants and the readily accessible and affordable health care system. As addressed in previous literature, preferences for mobile apps developed for diabetes management are different in different countries; Americans prefer apps that support their decision-making, while Chinese and Middle Eastern residents prefer app-based communication functions [40,41]. Korean people also benefited from an automated self-measured blood glucose upload built-in diabetes self-management app with physician response once a week [42]. In brief, patients in Asia and the Middle East prefer to seek advice from their health care teams directly through the communication app, while patients in western countries prefer to solve problems by themselves if the diabetes-specific app can provide adequate resources to support their decision-making. On the other hand, the language of most diabetes apps is English $(85.4 \%)$; this limits the selection of diabetes apps in Taiwan. Additionally, patients prefer free apps to paid apps [43]. In this era of knowledge explosion, patients can search for diabetes management articles online; however, they may not recognize whether the information in these articles is correct [44]. There is no one app that is suitable for all patients with diabetes. Development of diabetic self-management mobile apps in Taiwan also requires much user feedback [45]. However, even if a dedicated developed app that contains all suggested functions and articles beneficial for diabetes self-management were accessible, patients would not use all the built-in functions to enhance their self-care behavioral skills [46]. For the reasons addressed above, the application of LINE for diabetes care in Taiwan is appropriate in many aspects; it can be used to communicate with health care teams, can provide carefully selected articles that assist diabetes self-management, and is freely available. We also used a strategy of not providing too many messages at a time; therefore, participants could absorb the diabetes self-management knowledge in steps during the 12-week intervention period.

In the present study, we found when the diabetes-related distress scores for the participants were higher before the intervention, their diabetes distress was significantly reduced in both the mobile-based and telephone-based groups. Increasing numbers of studies are focusing on mobile-related devices or applications rather than telephone-based interventions due to the fact that such devices and applications are cost-effective, can reach large populations, suggest promising outcomes, and have expanded rapidly in the past decade [47-50]. This study also suggests that mobile-related applications are more cost-effective than telephone-based interventions and are very efficient. Previous studies have provided services that deliver interventions, including brief psychological therapies, mental health assessments, psychotropic medications, and social support, enhanced by patient-led case conferences aiming to optimize diabetes care. The results of these studies indicate a significant reduction in $\mathrm{HbA}_{1 \mathrm{c}}$ of $3.5 \%$, which was associated with reductions at 1-year follow-up [51]. Our study found that for the mobile-based intervention group, when we focused on people with diabetes whose diabetes distress scores were lower than the median score, there was a significant reduction in $\mathrm{HbA}_{1 \mathrm{c}}$ scores during the 12-week period. This can be explained by the fact that information seeking is one of the most important elements of coping strategies of chronic illness among patients who have comorbid depression [52]; immediate responses and conversation privacy are additional strengths of mobile-based interventions.

In this study, we found that the decrease of the PAID score with the mobile-based intervention was greater when the participants were younger and when their education levels were higher. This finding echoes those of previous studies indicating that people newly diagnosed with diabetes are willing to participate in self-management programs where their medical outcomes are being effectively targeted $[53,54]$.

\section{Limitations}

There were some limitations of this study. First, this study had a small sample size. Second, it did not randomly allocate participants to the 3 interventions. However, we compared the mobile-based group with the telephone-based and usual care groups and found manageable differences. Third, this study did not evaluate changes in behavior-related variables. Future studies are suggested to test the effects of this intervention in a broader sample and to evaluate both its behavioral and long-term effects.

\section{Conclusion}

Existing free social and communication apps are effective to improve glycemic control and reduce diabetes-specific distress in older adults with diabetes. For participants younger than 60 years, with higher educational levels, or with higher diabetes-related distress at baseline, the social and communication app reduced their distress scores more dramatically than those of participants in the other 2 groups after the intervention. In addition, for participants whose distress scores were below average at baseline, the social and communication app significantly improved their glycemic control. 


\section{Acknowledgments}

This work was supported by grant MOST-103-2314-B-006-038-MY3 from the Taiwan National Science Council. The authors appreciate Dr Ye-Fong Du for helping recruit the patients with diabetes for this study.

\section{Conflicts of Interest}

None declared.

\section{Multimedia Appendix 1}

Sample messages.

[DOCX File, 1508 KB-Multimedia Appendix 1]

\section{References}

1. Espeland MA, Erickson K, Neiberg RH, Jakicic JM, Wadden TA, Wing RR, Action for Health in Diabetes Brain Magnetic Resonance Imaging (Look AHEAD Brain) Ancillary Study Research Group. Brain and White Matter Hyperintensity Volumes After 10 Years of Random Assignment to Lifestyle Intervention. Diabetes Care 2016 May;39(5):764-771 [FREE Full text] [doi: $10.2337 / \mathrm{dc15-2230}$ ] [Medline: 27208378 ]

2. Rustveld L, Mansyur C, Jibaja-Weiss M. Effect of a bilingual diabetes education interactive telenovela on glycemic control among hispanic patients with type 2 diabetes: A randomized clinical trial. In: 141st APHA Annual Meeting. 2013 Nov 06 Presented at: 141st APHA Annual Meeting; November 6, 2013; Boston, MA URL: https://apha.confex.com/apha/141am/ webprogramadapt/Paper291264.html

3. Van Dyck D, De Greef K, Deforche B, Ruige J, Bouckaert J, Tudor-Locke CE, et al. The relationship between changes in steps/day and health outcomes after a pedometer-based physical activity intervention with telephone support in type 2 diabetes patients. Health Educ Res 2013 Jun;28(3):539-545. [doi: 10.1093/her/cyt038] [Medline: 23492248]

4. American Association of Diabetes Educators. An Effective Model of Diabetes Care and Education: Revising the AADE7 Self-Care Behaviors. Diabetes Educ 2020 Apr;46(2):139-160. [doi: 10.1177/0145721719894903] [Medline: 31928334]

5. Botsis T, Hartvigsen G. Current status and future perspectives in telecare for elderly people suffering from chronic diseases. J Telemed Telecare 2008;14(4):195-203. [doi: 10.1258/jtt.2008.070905] [Medline: 18534954]

6. Fischer HH, Moore SL, Ginosar D, Davidson AJ, Rice-Peterson CM, Durfee MJ, et al. Care by cell phone: text messaging for chronic disease management. Am J Manag Care 2012 Feb;18(2):e42-e47 [FREE Full text] [Medline: 22435883]

7. Barr N, Vania D, Randall G, Mulvale G. Impact of information and communication technology on interprofessional collaboration for chronic disease management: a systematic review. J Health Serv Res Policy 2017 Jan 01:1355819617714292. [doi: 10.1177/1355819617714292] [Medline: 28587494]

8. Greenwood DA, Gee PM, Fatkin KJ, Peeples M. A Systematic Review of Reviews Evaluating Technology-Enabled Diabetes Self-Management Education and Support. J Diabetes Sci Technol 2017 Sep;11(5):1015-1027. [doi: 10.1177/1932296817713506] [Medline: 28560898]

9. Clarke J, Proudfoot J, Ma H. Mobile Phone and Web-based Cognitive Behavior Therapy for Depressive Symptoms and Mental Health Comorbidities in People Living With Diabetes: Results of a Feasibility Study. JMIR Ment Health 2016 May 31;3(2):e23 [FREE Full text] [doi: 10.2196/mental.5131] [Medline: 27245948]

10. Martinez M, Park SB, Maison I, Mody V, Soh LS, Parihar HS. iOS Appstore-Based Phone Apps for Diabetes Management: Potential for Use in Medication Adherence. JMIR Diabetes 2017 Jul 11;2(2):e12 [FREE Full text] [doi: 10.2196/diabetes.6468] [Medline: $\underline{\text { 30291096] }}$

11. Brindal E, Hendrie GA, Freyne J. Combining Persuasive Technology With Behavioral Theory to Support Weight Maintenance Through a Mobile Phone App: Protocol for the MotiMate App. JMIR Res Protoc 2016 Jan 08;5(1):e5 [FREE Full text] [doi: 10.2196/resprot.4664] [Medline: 26747725]

12. Jeffrey B, Bagala M, Creighton A, Leavey T, Nicholls S, Wood C, et al. Mobile phone applications and their use in the self-management of Type 2 Diabetes Mellitus: a qualitative study among app users and non-app users. Diabetol Metab Syndr 2019;11:84 [FREE Full text] [doi: 10.1186/s13098-019-0480-4] [Medline: 31636719]

13. Vehi J, Regincós Isern J, Parcerisas A, Calm R, Contreras I. Impact of Use Frequency of a Mobile Diabetes Management App on Blood Glucose Control: Evaluation Study. JMIR Mhealth Uhealth 2019 Mar 07;7(3):e11933 [FREE Full text] [doi: 10.2196/11933] [Medline: 30843865]

14. Ralston JD, Hirsch IB, Hoath J, Mullen M, Cheadle A, Goldberg HI. Web-based collaborative care for type 2 diabetes: a pilot randomized trial. Diabetes Care 2009 Feb;32(2):234-239 [FREE Full text] [doi: 10.2337/dc08-1220] [Medline: $\underline{19017773]}$

15. McMahon GT, Gomes HE, Hickson HS, Hu TM, Levine BA, Conlin PR. Web-based care management in patients with poorly controlled diabetes. Diabetes Care 2005 Jul;28(7):1624-1629 [FREE Full text] [Medline: 15983311] 
16. Bond GE, Burr R, Wolf FM, Price M, McCurry SM, Teri L. The effects of a web-based intervention on the physical outcomes associated with diabetes among adults age 60 and older: a randomized trial. Diabetes Technol Ther 2007 Feb;9(1):52-59 [FREE Full text] [doi: 10.1089/dia.2006.0057] [Medline: 17316098]

17. Wu Y, Yao X, Vespasiani G, Nicolucci A, Dong Y, Kwong J, et al. Mobile App-Based Interventions to Support Diabetes Self-Management: A Systematic Review of Randomized Controlled Trials to Identify Functions Associated with Glycemic Efficacy. JMIR Mhealth Uhealth 2017 Mar 14;5(3):e35 [FREE Full text] [doi: 10.2196/mhealth.6522] [Medline: 28292740]

18. Bonoto BC, de AVE, Godói IP, de LLLP, Godman B, Bennie M, et al. Efficacy of Mobile Apps to Support the Care of Patients With Diabetes Mellitus: A Systematic Review and Meta-Analysis of Randomized Controlled Trials. JMIR Mhealth Uhealth 2017 Mar 01;5(3):e4 [FREE Full text] [doi: 10.2196/mhealth.6309] [Medline: 28249834]

19. Jeon E, Park H. Development of the IMB Model and an Evidence-Based Diabetes Self-management Mobile Application. Healthc Inform Res 2018 Apr;24(2):125-138 [FREE Full text] [doi: 10.4258/hir.2018.24.2.125] [Medline: 29770246]

20. Hu Y, Chiu C. An Ecological Study of the Relationship Between Online Health Information Seeking Behavior and Mortality Rates in Taiwan. Gerontologist 2015 Nov 01;55:243. [doi: 10.1093/geront/gnv565.22]

21. Kathryn ZM, Madden M. Pew Research Center. 2012 Jun 06. Older adults and internet use URL: https://www. pewresearch.org/internet/2012/06/06/older-adults-and-internet-use/ [accessed 2020-05-07]

22. Verrusio W, Gianturco V, Cacciafesta M, Marigliano V, Troisi G, Ripani M. Fall prevention in the young old using an exoskeleton human body posturizer: a randomized controlled trial. Aging Clin Exp Res 2017 Apr;29(2):207-214. [doi: 10.1007/s40520-016-0540-7] [Medline: 26849366]

23. Laufer Y, Dar G, Kodesh E. Does a Wii-based exercise program enhance balance control of independently functioning older adults? A systematic review. Clin Interv Aging 2014;9:1803-1813 [FREE Full text] [doi: 10.2147/CIA.S69673] [Medline: 25364238]

24. Onuki M, Arita M, Inoue E, Tsujishita M. Influence of Virtual Reality Gaming Using Bio-sensing Technology on the Motor Function of the Elderly. Rigakuryoho kagaku 2015;30(6):811-815. [doi: 10.1589/rika.30.811]

25. Huang S, Pan Y, Chen MS. My Health Bank 2.0-making a patron saint for people's health. J Formos Med Assoc 2017 Feb;116(2):69-71 [FREE Full text] [doi: 10.1016/j.jfma.2016.05.008] [Medline: 27421173]

26. Bricker JB, Mull KE, Kientz JA, Vilardaga R, Mercer LD, Akioka KJ, et al. Randomized, controlled pilot trial of a smartphone app for smoking cessation using acceptance and commitment therapy. Drug Alcohol Depend 2014 Oct 1;143:87-94. [doi: 10.1016/j.drugalcdep.2014.07.006] [Medline: 25085225]

27. BinDhim NF, McGeechan K, Trevena L. Who Uses Smoking Cessation Apps? A Feasibility Study Across Three Countries via Smartphones. JMIR Mhealth Uhealth 2014;2(1):e4 [FREE Full text] [doi: 10.2196/mhealth.2841] [Medline: 25098439]

28. Grindrod KA, Li M, Gates A. Evaluating user perceptions of mobile medication management applications with older adults: a usability study. JMIR Mhealth Uhealth 2014;2(1):e11 [FREE Full text] [doi: 10.2196/mhealth.3048] [Medline: 25099993]

29. Waring ME, Moore STA, Xiao RS, Lombardini LM, Allison JJ, Rosal MC, et al. Pregnant women's interest in a website or mobile application for healthy gestational weight gain. Sex Reprod Healthc 2014 Dec;5(4):182-184. [doi: 10.1016/j.srhc.2014.05.002] [Medline: 25433828]

30. Shih R, Lee C, Cheng T. Effects of English Spelling Learning Experience through a Mobile LINE APP for College Students. Procedia Soc Behav Sci 2015 Feb 12;174:2634-2638 [FREE Full text] [doi: 10.1016/j.sbspro.2015.01.945]

31. Yu-Tzu C. ZDNet. 2013 Nov 27. Taiwan market has great potential for Line URL: https://www.zdnet.com/article/ taiwan-market-has-great-potential-for-line/ [accessed 2020-04-01]

32. Breland JY, Yeh VM, Yu J. Adherence to evidence-based guidelines among diabetes self-management apps. Transl Behav Med 2013 Sep;3(3):277-286 [FREE Full text] [doi: 10.1007/s13142-013-0205-4] [Medline: 24073179]

33. Cheng NY. National Taiwan University of Arts. 2017. An Investigation on Consumers' Preference of "LINE" Stickers in Taiwan. Thesis in Chinese URL: https://hdl.handle.net/11296/3u8fvp [accessed 2020-05-07]

34. Welch G, Weinger K, Anderson B, Polonsky WH. Responsiveness of the Problem Areas In Diabetes (PAID) questionnaire. Diabet Med 2003 Jan;20(1):69-72. [Medline: 12519323]

35. Radloff LS. The CES-D Scale. Appl Psychol Meas 2016 Jul 26;1(3):385-401. [doi: 10.1177/014662167700100306]

36. Irwin M, Artin KH, Oxman MN. Screening for depression in the older adult: criterion validity of the 10-item Center for Epidemiological Studies Depression Scale (CES-D). Arch Intern Med 1999;159(15):1701-1704. [Medline: 10448771]

37. Andresen EM, Malmgren JA, Carter WB, Patrick DL. Screening for depression in well older adults: evaluation of a short form of the CES-D (Center for Epidemiologic Studies Depression Scale). Am J Prev Med 1994 Mar;10(2):77-84. [Medline: $\underline{8037935]}$

38. Klasnja P, Pratt W. Healthcare in the pocket: mapping the space of mobile-phone health interventions. J Biomed Inform 2012 Feb;45(1):184-198 [FREE Full text] [doi: 10.1016/j.jbi.2011.08.017] [Medline: 21925288]

39. Echt KV. Designing Web-based health information for older adults: Visual considerations and design directives. In: Older Adults, Health Information, and the World Wide Web. Mahwah, NJ: Lawrence Erlbaum Associates; 2002:61-87.

40. Wu Y, Zhou Y, Wang X, Zhang Q, Yao X, Li X, et al. A Comparison of Functional Features in Chinese and US Mobile Apps for Diabetes Self-Management: A Systematic Search in App Stores and Content Analysis. JMIR Mhealth Uhealth 2019 Aug 28;7(8):e13971 [FREE Full text] [doi: 10.2196/13971] [Medline: 31464191] 
41. Alanzi T, Istepanian R, Philip N, Sungoor A. A Study on Perception of Managing Diabetes Mellitus through Social Networking in the Kingdom of Saudi Arabia. IFMBE Proceedings 2014:41-10. [doi: 10.1007/978-3-319-00846-2 470]

42. Yang Y, Lee EY, Kim H, Lee S, Yoon K, Cho J. Effect of a Mobile Phone-Based Glucose-Monitoring and Feedback System for Type 2 Diabetes Management in Multiple Primary Care Clinic Settings: Cluster Randomized Controlled Trial. JMIR Mhealth Uhealth 2020 Feb 26;8(2):e16266 [FREE Full text] [doi: 10.2196/16266] [Medline: 32130172]

43. Arnhold M, Quade M, Kirch W. Mobile applications for diabetics: a systematic review and expert-based usability evaluation considering the special requirements of diabetes patients age 50 years or older. J Med Internet Res 2014;16(4):e104 [FREE Full text] [doi: 10.2196/jmir.2968] [Medline: 24718852]

44. AlQarni ZA, Yunus F, Househ MS. Health information sharing on Facebook: An exploratory study on diabetes mellitus. J Infect Public Health 2016;9(6):708-712 [FREE Full text] [doi: 10.1016/j.jiph.2016.08.015] [Medline: 27618634]

45. Chao DY, Lin TM, Ma W. Enhanced Self-Efficacy and Behavioral Changes Among Patients With Diabetes: Cloud-Based Mobile Health Platform and Mobile App Service. JMIR Diabetes 2019 May 10;4(2):e11017 [FREE Full text] [doi: 10.2196/11017] [Medline: 31094324]

46. Jeon E, Park H. Experiences of Patients With a Diabetes Self-Care App Developed Based on the Information-Motivation-Behavioral Skills Model: Before-and-After Study. JMIR Diabetes 2019 Apr 18;4(2):e11590 [FREE Full text] [doi: 10.2196/11590] [Medline: 30998218]

47. Jennings L, Omoni A, Akerele A, Ibrahim Y, Ekanem E. Disparities in mobile phone access and maternal health service utilization in Nigeria: a population-based survey. Int J Med Inform 2015 May;84(5):341-348. [doi: 10.1016/j.ijmedinf.2015.01.016] [Medline: 25737460]

48. Baum RA, Epstein JN, Kelleher K. Healthcare reform, quality, and technology: ADHD as a case study. Curr Psychiatry Rep 2013 Jul;15(7):369 [FREE Full text] [doi: 10.1007/s11920-013-0369-0] [Medline: 23712720]

49. Vandelanotte C, Müller AM, Short CE, Hingle M, Nathan N, Williams SL, et al. Past, Present, and Future of eHealth and mHealth Research to Improve Physical Activity and Dietary Behaviors. J Nutr Educ Behav 2016 Mar;48(3):219-228.e1. [doi: 10.1016/j.jneb.2015.12.006] [Medline: 26965100]

50. Ubhi HK, Kotz D, Michie S, van SOCP, Sheard D, Selladurai A, et al. Comparative analysis of smoking cessation smartphone applications available in 2012 versus 2014. Addict Behav 2016 Jul;58:175-181 [FREE Full text] [doi: 10.1016/j.addbeh.2016.02.026] [Medline: 26950256]

51. Doherty AM, Gayle C, Morgan-Jones R, Archer N, Laura-Lee, Ismail K, et al. Improving quality of diabetes care by integrating psychological and social care for poorly controlled diabetes: 3 Dimensions of Care for Diabetes. Int J Psychiatry Med 2016;51(1):3-15. [doi: 10.1177/0091217415621040] [Medline: 26681232]

52. Felton BJ, Revenson TA, Hinrichsen GA. Stress and coping in the explanation of psychological adjustment among chronically ill adults. Soc Sci Med 1984;18(10):889-898. [doi: 10.1016/0277-9536(84)90158-8] [Medline: 6729517]

53. Davies MJ, Heller S, Skinner TC, Campbell MJ, Carey ME, Cradock S, et al. Effectiveness of the diabetes education and self management for ongoing and newly diagnosed (DESMOND) programme for people with newly diagnosed type 2 diabetes: cluster randomised controlled trial. BMJ 2008 Mar 1;336(7642):491-495 [FREE Full text] [doi: 10.1136/bmj.39474.922025.BE] [Medline: 18276664]

54. Skinner TC, Carey ME, Cradock S, Daly H, Davies MJ, Doherty Y, et al. Diabetes Education and Self-Management for Ongoing and Newly Diagnosed (DESMOND): process modelling of pilot study. Patient Educ Couns 2006 Dec;64(1-3):369-377. [doi: 10.1016/j.pec.2006.04.007] [Medline: 17011154]

\section{Abbreviations}

AADE: American Association of Diabetes Educators

$\mathbf{H b A}_{1 \mathbf{c}}$ : hemoglobin $\mathrm{A}_{1 \mathrm{c}}$

PAID: Problem Areas in Diabetes Scale

CES-D: Center for Epidemiological Studies Depression Scale

Edited by G Eysenbach; submitted 15.03.19; peer-reviewed by A Fioravanti, C Mamillapalli, S Baptista, M Quintana; comments to
author 12.12.19; revised version received 30.01.20; accepted 29.03.20; published 02.06.20
Please cite as:
Chiu CJ, Yu YC, Du YF, Yang YC, Chen JY, Wong LP, Tanasugarn C
Comparing a Social and Communication App, Telephone Intervention, and Usual Care for Diabetes Self-Management: 3 -Arm
Quasiexperimental Evaluation Study
JMIR Mhealth Uhealth 2020;8(6):e14024
URL: $\underline{\text { https://mhealth.jmir.org/2020/6/e14024 }}$
doi: $\underline{10.2196 / 14024}$
PMID: $\underline{32484448}$


(C) Ching-Ju Chiu, Yung-Chen Yu, Ye-Fong Du, Yi-Ching Yang, Jou-Yin Chen, Li-Ping Wong, Chanuantong Tanasugarn. Originally published in JMIR mHealth and uHealth (http://mhealth.jmir.org), 02.06.2020. This is an open-access article distributed under the terms of the Creative Commons Attribution License (https://creativecommons.org/licenses/by/4.0/), which permits unrestricted use, distribution, and reproduction in any medium, provided the original work, first published in JMIR mHealth and uHealth, is properly cited. The complete bibliographic information, a link to the original publication on http://mhealth.jmir.org/, as well as this copyright and license information must be included. 